\title{
A TOPSIS method based on intuitionistic fuzzy values: a case study of North African airports
}

\author{
Houssine Tlig $^{\mathrm{a}^{*}}$ and Abdelwaheb Rebai ${ }^{\mathrm{b}}$
}

${ }^{a}$ Department of Quantitativ Methods, ISG, Gabes University 6029, Tunisia

${ }^{b}$ Department of Quantitativ Methods, FSEG, Sfax University 3029, Tunisia

\section{H R O N I C L E}

Article history:

Received: October 1, 2016

Received in revised format: No-

vember 16, 2016

Accepted: April 14, 2017

Available online:

April 16, 2017

Keywords:

TOPSIS

Multi criteria decision making

Intuitionistic fuzzy value

Airports

\section{A B S T R A C T}

\begin{abstract}
In this paper we develop a fuzzy TOPSIS method based on intuitionistic fuzzy values to solve multiple criteria decision making problems in which the performance rating of alternatives values and the weights of criteria are given by linguistic terms. Arithmetic operations between intuitionistic fuzzy values are used for normalizing imprecise ratings and weights of criteria. In order to demonstrate the effectiveness of the suggested method, we propose a case study aiming to evaluate and compare the service quality of five major airports in North Africa. The suggested method helps manager of airports know the needs of passengers and the priority of enhancing service items.
\end{abstract}

\section{Introduction}

TOPSIS (technique for order preference by similarity to ideal solution), initially developed by Hwang and Yoon (1981), is an important classical multiple criteria decision making method (MCDM). It consists to calculate a closeness coefficient that can be used for ranking the set of alternatives with respect to the set of criteria. In the classical TOPSIS method, the performance rating and the weights of criteria are given by crisp values. However, with the complexity of the environment and under many conditions, crisp values cannot model adequately some real world situations because human judgment and preference are often ambiguous and cannot be estimated exactly (Kuo et al., 2007). Fuzzy set theory (Zadeh, 1965) emerged as an alternative way to treat information from human judgment and preference, it has been successfully applied to handle the imprecision in the TOPSIS method. The obtained technique, called fuzzy TOPSIS, has been investigated in many works (Chen, 2000; Chen et al., 2006; Chen \& Hwang, 1992; Chen \& Tzeng, 2004; Jahanshahloo et al., 2006; Liang, 1999; Wang \& Elhag, 2006; Wang \& Lee, 2007; Wang et al., 2007; Yeh et al., 2000; Yeh \& Deng, 2004). A review on fuzzy TOPSIS methods can be found in Kuo et al. (2007).

\footnotetext{
* Corresponding author. Tel.: +21622181437

E-mail address: housni.tlig@gmail.com (H. Tlig) 
Atanassov (1986) generalized the idea of fuzzy set to intuitionistic fuzzy set (IFS) which takes into account the hesitation of decision makers. IFS treats vague information by considering membership function and non-membership function and this can minimize the imprecision degree in complex systems. Intuitionistic fuzzy TOPSIS has been applied in some studies (Boran et al., 2009; Xu, 2007; Tan \& Chen, 2010; Wei et al., 2013; Aloini et al., 2014; Zhang \& Yu, 2012; Joshi \& Kumar, 2014).

In this paper, we develop a fuzzy TOPSIS method based on intuitionistic fuzzy values (IFV-TOPSIS) to solve MCDM problems in which the performance rating values and the weights of criteria are given by linguistic terms. Arithmetic operations between intuitionistic fuzzy values are used for normalizing imprecise ratings and weights of criteria. In order to demonstrate the effectiveness of the suggested method, we propose a case study aiming to evaluate and compare the service quality of major five airports in North Africa.

The rest of the paper is organized as follows. Section 2 introduces the TOPSIS method. Section 3 illustrates intuitionistic fuzzy set (IFS). Section 4 describes developed TOPSIS method to solve MCDM problems when ratings and weights of criteria are considered as intuitionistic fuzzy values. Section 5 proposes a case study aiming to evaluate the service quality of five airports in North Africa. The paper is concluded in Section 6 .

\section{TOPSIS method}

TOPSIS method consists to calculate a closeness coefficient for each alternative based on distances between the target alternative and the positive and the negative-ideal solutions. The best alternative has the shortest distance from the positive-ideal solution (PIS) and the farthest from the negative-ideal solution (NIS).

Let a multi criteria decision making process with $\mathrm{n}$ alternatives $A_{1}, A_{2}, \ldots, A_{n}$ and $\mathrm{m}$ criteria $C_{1}, C_{2}, \ldots, C_{m}$. Each alternative is evaluated with respect to the $\mathrm{m}$ criteria. All the values/ratings are assigned to alternatives with respect to decision matrix denoted by $X\left(x_{i j}\right)_{n \times m}$. Let $W=\left(w_{1}, w_{2}, \ldots, w_{m}\right)$ be the weight vector criteria, satisfying $\sum_{i=1}^{m} w_{i}=1$. The TOPSIS method can be summarized on the following steps:

i. First, normalize the decision matrix using the following transformation for each $r_{i j}$

$$
r_{i j}=\frac{x_{i j}}{\sqrt{\sum_{i=1}^{n} x_{i j}^{2}}}, i=1, \ldots, n ; j=1, \ldots, m
$$

Then, multiply the columns of the normalized decision matrix by the associated weights. The weighted and normalized decision matrix is obtained as:

$$
v_{i j}=w_{j} \times r_{i j}, \quad i=1, \ldots, n ; j=1, \ldots, m
$$

where $w_{j}$ represents the weight of the jth criterion.

ii. Determine a positive- ideal and a negative -ideal solution: the positive- ideal and the negative- ideal alternatives are determined, respectively, as follows:

$$
\begin{aligned}
& A^{+}=\left(v_{1}^{+}, v_{2}^{+}, \ldots ., v_{m}^{+}\right)=\left\{\left(\max _{j} v_{i j} ; j \in \Omega_{b}\right),\left(\min _{j} v_{i j} ; j \in \Omega_{c}\right)\right\} \\
& A^{-}=\left(v_{1}^{-}, v_{2}^{-}, \ldots ., v_{m}^{-}\right)=\left\{\left(\min _{j} v_{i j} ; j \in \Omega_{b}\right),\left(\max _{j} v_{i j} ; j \in \Omega_{c}\right)\right\}
\end{aligned}
$$

where $\Omega_{b}$ is the set of benefit criteria and $\Omega_{c}$ is the set of cost criteria. 
iii. Calculate the distance of each alternative from positive- ideal and negative-ideal alternatives: the Euclidean distances for each alternative are, respectively, given by:

$$
\begin{aligned}
& S_{i}^{+}=\sqrt{\sum_{j=1}^{m}\left(v_{i j}-v_{j}^{+}\right)^{2}}, \quad i=1, \ldots ., n \\
& S_{i}^{-}=\sqrt{\sum_{j=1}^{m}\left(v_{i j}-v_{j}^{-}\right)^{2}}, \quad i=1, \ldots ., n
\end{aligned}
$$

iv. Calculate a closeness coefficient for each alternative as

$$
R C_{i}=\frac{s_{i}^{-}}{s_{i}^{+}+s_{i}^{-}}, \quad i=1, \ldots ., n ; 0 \leq R C_{i} \leq 1
$$

v. Rank the alternatives according to the closeness coefficients.

\section{Intuitionistic fuzzy sets}

In this section, we review the basic concepts relates to intuitionistic fuzzy sets.

Definition 3.1 Atanassov (1986). An intuitionistic fuzzy set $A$ in $X=\{x\}$ is given by:

$$
X=\left\{\left(x, \mu_{A}(x), v_{A}(x)\right) ; x \in X\right\}
$$

where, $\mu_{A}(x): X \rightarrow[0,1], v_{A}(x): X \rightarrow[0,1]$ and $0 \leq \mu_{A}(x)+v_{A}(x) \leq 1 \quad \forall x \in X . \quad \mu_{A}(x)$ and $v_{A}(x)$ are respectively the degree of membership and non-membership function of $x$ to $A$.

If we use a membership function $t_{A}$ and a non-membership function $f_{A}$ to denote the lower bounds on $\mu_{A}$, then, the degree of membership of $x$ in the intuitionistic fuzzy set $A$ is bounded to a subinterval $\left[t_{A}(x), 1-f_{A}(x)\right]$. The interval $\left[t_{A}(x), 1-f_{A}(x)\right]$ is considered as intuitionistic fuzzy value and Eq. (1) can be replaced with

$$
A=\left\{\left\langle x,\left[t_{A}(x), 1-f_{A}(x)\right]\right\rangle ; x \in X\right\}
$$

\subsection{Basic relation and operation on intuitionistic fuzzy sets}

Let $A=\left[t_{A}, 1-f_{A}\right]$ and $A=\left[t_{B}, 1-f_{B}\right]$ be two IFV. The basic operations between as intuitionistic fuzzy values can be summarized as follow:

$$
\begin{aligned}
& A \oplus B=\left[t_{A}+t_{B},\left(1-f_{A}\right)+\left(1-f_{B}\right)\right] \\
& A-B=\left[t_{A}-t_{B},\left(1-f_{A}\right)-\left(1-f_{B}\right)\right] \\
& A \otimes B=\left[t_{A} t_{B},\left(1-f_{A}\right)\left(1-f_{B}\right)\right] \\
& A \oplus B=\left[t_{A}+t_{B},\left(1-f_{A}\right)+\left(1-f_{B}\right)\right]
\end{aligned}
$$

Definition 3.2. Szmidt and Kacprzyk (2000). Let $A=\left\{\left(t_{A}(x), 1-f_{A}(x)\right) ; x \in X\right\}$ and $B=\left\{\left(t_{B}(x), 1-f_{B}(x)\right) ; x \in X\right\}$ be two IFS in $X=\left\{x_{1}, x_{2}, \ldots, x_{n}\right\}$. The normalized Euclidean distance between $A$ and $B$ is given by

$$
d(A, B)=\sqrt{\frac{1}{2 n} \sum_{i=1}^{n}\left[\left(t_{A}\left(x_{i}\right)-t_{B}\left(x_{i}\right)\right)^{2}+\left(f_{A}\left(x_{i}\right)-f_{B}\left(x_{i}\right)\right)^{2}\right]}
$$




\section{The proposed interval-valued fuzzy TOPSIS}

Suppose a decision process composed by $k$ decision-makers which are responsible for selecting $n$ alternatives $\left(a_{1}, a_{2}, \ldots, a_{n}\right)$ under $m$ criteria $\left(C_{1}, C_{2}, \ldots, C_{m}\right)$. Criteria can be classified into benefit criteria (B) and cost criteria $(C)$. Further assume that the performance ratings and the weights of the criteria are evaluated in linguistic terms represented by intuitionistic fuzzy values. The suggested IFV-TOPSIS method is described as follow:

Aggregate the performance ratings and perform normalization

Let $x_{i j k}=\left(t_{x_{j j s}}, 1-f_{x_{j j}}\right), x_{i j k} \geq 0, i=1, \ldots ., n, j=1, \ldots ., m, s=1, \ldots ., k$, be the performance rating assigned to alternative $A_{i}$ by decision maker $D_{k}$ for criterion $C_{j}$. The aggregated performance rating, $x_{i j}=\left(t_{x_{i j}}, 1-f_{x_{i j}}\right)$ of alternative $A_{i}$ under criterion $C_{j}$ can be evaluated as:

$$
x_{i j}=(1 / k) \otimes\left(x_{i j 1}+x_{i j 2}+\ldots+x_{i j k}\right)
$$

The aggregated, i.e. $x_{i j}=\left(t_{i j}, 1-f_{i j}\right)$, can be normalized as follow:

$$
\begin{aligned}
& r_{i j}=\left(\frac{t_{x_{i j}}}{t_{x_{i j}}^{+}}, \frac{\left(1-f_{x_{i j}}\right)}{\left(1-f_{x_{i j}}\right)^{+}}\right), \\
& t_{i j}^{+}=\max _{i} t_{i j} \text { and }\left(1-f_{x_{i j}}\right)^{+}=\max _{i}\left(1-f_{x_{i j}}\right) \text { for } j \in B ; \\
& r_{i j}=\left(\frac{t_{x_{i j}}^{-}}{t_{x_{i j}}}, \frac{\left(1-f_{x_{i j}}\right)^{-}}{\left(1-f_{x_{i j}}\right)}\right), \\
& t_{i j}^{-}=\min _{i} t_{i j} \text { and }\left(1-f_{x_{i j}}\right)^{-}=\min _{i}\left(1-f_{x_{i j}}\right) \text { for } j \in C,
\end{aligned}
$$

Aggregate the importance weights and perform normalization

Let $w_{j k}=\left(t_{w_{j s}}, 1-f_{w_{j s}}\right), x_{i j s} \geq 0, j=1, \ldots ., m, s=1, \ldots ., k$ be the importance weight given by decision maker $D_{k}$ to criterion $C_{j}$. The aggregated importance weight, $w_{j}=\left(t_{w_{j}}, 1-f_{w_{j}}\right)$ of criterion $C_{j}$ can be calculated as:

$$
w_{j}=\frac{1}{k} \otimes\left(w_{j 1} \oplus w_{j 2} \oplus \ldots . \oplus w_{j k}\right)
$$

The aggregated weights can be normalized as follows,

$$
w_{j}^{\prime}=\frac{w_{j}}{\sum_{j=1}^{m} w_{j}}=\left(\frac{t_{w_{j}}}{\sum_{j=1}^{m} t_{w_{j}}}, \frac{1-f_{w_{j}}}{m-\sum_{j=1}^{m} f_{w_{j}}}\right)
$$

where $w_{j}^{\prime}$ denotes the normalized $w_{j}$

\section{Construct the normalized decision matrix}

The weighted normalized fuzzy decision matrix is given by $V_{i j}=\left[v_{i j}\right]_{n \times m}$ where $v_{i j}=r_{i j} \otimes w_{j}^{\prime}$. The multiply operator can be applied as: 


$$
v_{i j}=\left[t_{\left(r_{i j} \times w_{j}^{\prime}\right)},(1-f)_{\left(\left(r_{i j} \times w_{j}^{\prime}\right)\right)}\right]=\left[t_{r_{i j}} \times t_{w_{j}^{\prime}},\left(1-f_{r_{i j}}\right) \times\left(1-f_{w_{j}^{\prime}}\right)\right] \text {. }
$$

\section{Determinate ideal and ideal negative solutions}

Positive-Ideal and negative- ideal solutions can be defined as:

$$
\begin{aligned}
& A^{+}=(1,1), \quad j \in \Omega_{b} \\
& A^{-}=(0,0), \quad j \in \Omega_{c}
\end{aligned}
$$

According to definition (2.2), the distance between each alternative and $A^{+}$(and $A^{-}$) can be obtained as:

$$
\begin{aligned}
& d_{i}^{+}=\sqrt{\frac{1}{2 m} \sum_{j=1}^{m}\left[\left(t_{v_{i j}}-1\right)^{2}+\left(f_{v_{i j}}\right)^{2}\right]}, \quad i=1, \ldots ., n \\
& d_{i}^{-}=\sqrt{\frac{1}{2 m} \sum_{j=1}^{m}\left[\left(t_{v_{i j}}\right)^{2}+\left(f_{v_{i j}}-1\right)^{2}\right]}, \quad i=1, \ldots, n
\end{aligned}
$$

where $d_{i}^{+}$denotes the distance between each alternative and $A^{+}$and $d_{i}^{-}$denotes the distance between each alternative and $A^{-}$.

\section{Calculate the closeness coefficient}

The closeness coefficient of each alternative can be obtained as:

$$
C_{i}=\frac{d_{i}^{-}}{d_{i}^{+}+d_{i}^{-}}, \quad i=1, \ldots, n
$$

According to the closeness coefficient, we can determine the ranking order of all alternatives and select the best one from them.

\section{A case study of North Africa airports}

The quality of service is a basic performance indicator for the operation of an airport. High service quality may have a significant impact in promoting future tourism and business activities. Thus, the evaluation of the quality of services has become an important issue for airport management. As we know, tourism is an economic factor of the North African countries. Thus, governments of these countries have recently become interested in evaluating the service quality of their airports in order to confront the intense competition that characterizes this sector.

In this paper, the proposed IFV- TOPSIS method is applied to evaluate the service quality of five major airports in north Africa; Houari Boumedienne Airport $\left(\mathrm{A}_{1}\right)$, Cairo International Airport $\left(\mathrm{A}_{2}\right)$, Carthage International Airport $\left(\mathrm{A}_{3}\right)$ Mohammed V International Airport $\left(\mathrm{A}_{4}\right)$, and Tripoli International Airport $\left(\mathrm{A}_{5}\right), .7$ benefic criteria (B) and 3 cost criteria (C) have been used in the study; Safety record (B), security (B), Seating comfort (B), Courtesy of employees (B), Neat appearance of employees (B), Availability of non-stop flight (B), Promptness and accuracy of baggage delivery (B), pollution (C), ticket price (C) and redtardness (C).

To conduct the study, 200 questionnaires are sent out to licensed tour guides in 15 general travel agencies in Tunisia. The reason of the choice of these respondents was that we wished respondents had the experience of traveling with all airlines to be evaluated. The licensed tour guides were the most natural choices due to their frequent travels. Each decision maker has presented his assessment based on linguistic variable for rating performance and importance of each criterion by a linguistic variable. For 
each linguistic variable, we assigned an intuitionistic fuzzy value. These values are registered in Table 1 and Table 2.

Table 1

Definitions of linguistic variables for the ratings

\begin{tabular}{cc}
\hline Very poor & $(0.1 ; 0.8)$ \\
poor & $(0,2 ; 0.67)$ \\
Fair & $(0.3 ; 0.66)$ \\
good & $(0.4 ; 0.60)$ \\
Very good & $(0.5 ; 0.44)$ \\
\hline
\end{tabular}

Table 2

Definitions of linguistic variables for the importance of each criterion

\begin{tabular}{cc}
\hline Very low & $(0.11 ; 0.78)$ \\
low & $(0,18 ; 0.66)$ \\
Fair & $(0.22 ; 0.56)$ \\
high & $(0.4 ; 0.49)$ \\
Very high & $(0.5 ; 0.34)$ \\
\hline
\end{tabular}

After obtaining the passengers' perception, we used first equations (11) and (14) to calculate the rating of alternatives with respect to each criterion and the importance of the criteria. The intuitionistic fuzzy valued decision matrix is given by Table 3 .

\section{Table 3}

The intuitionistic fuzzy valued decision matrix and weights

\begin{tabular}{ccccccc}
\hline & $\mathrm{A}_{1}$ & $\mathrm{~A}_{2}$ & $\mathrm{~A}_{3}$ & $\mathrm{~A}_{4}$ & $\mathrm{~A}_{5}$ & weights \\
\hline $\mathrm{C}_{1}$ & $(0.18 ; 0.27)$ & $(0.20 ; 0.63)$ & $(0.33 ; 0.22)$ & $(0.34 ; 0.23)$ & $(0.13 ; 0.78)$ & $(0.33 ; 0.29)$ \\
$\mathrm{C}_{2}$ & $(0.25 ; 0.16)$ & $(0.31 ; 0.58)$ & $(0.42 ; 0.34)$ & $(0.39 ; 0.35)$ & $(0.20 ; 0.59)$ & $(0.50 ; 0.34)$ \\
$\mathrm{C}_{3}$ & $(0.31 ; 0.14)$ & $(0.42 ; 0.33)$ & $(0.46 ; 0.28)$ & $(0.46 ; 0.29)$ & $(0.21 ; 0.57)$ & $(0.33 ; 0.23)$ \\
$\mathrm{C}_{4}$ & $(0.13 ; 0.78)$ & $(0.17 ; 0.61)$ & $(0.21 ; 0.53)$ & $(0.20 ; 0.54)$ & $(0.10 ; 0.79)$ & $(0.66 ; 0.19)$ \\
$\mathrm{C}_{5}$ & $(0.23 ; 0.74)$ & $(0.24 ; 0.70)$ & $(0.27 ; 0.44)$ & $(0.31 ; 0.40)$ & $(0.19 ; 0.80)$ & $(0.31 ; 0.44)$ \\
$\mathrm{C}_{6}$ & $(0.22 ; 0.76)$ & $(0.31 ; 0.54)$ & $(0.38 ; 0.47)$ & $(0.37 ; 0.47)$ & $(0.18 ; 0.77)$ & $(0.40 ; 0.61)$ \\
$\mathrm{C}_{7}$ & $(0.33 ; 0.24)$ & $(0.33 ; 0.28)$ & $(0.34 ; 0.30)$ & $(0.33 ; 0.31)$ & $(0.22 ; 0.38)$ & $(0.52 ; 0.19)$ \\
$\mathrm{C}_{8}$ & $(0.21 ; 0.6)$ & $(0.31 ; 0.68)$ & $(0.22 ; 0.58)$ & $(0.21 ; 0.59)$ & $(0.64 ; 0.13)$ & $(0.28 ; 0.54)$ \\
$\mathrm{C}_{9}$ & $(0.51 ; 0.2)$ & $(0.42 ; 0.44)$ & $(0.36 ; 0.38)$ & $(0.37 ; 0.39)$ & $(0.57 ; 0.2)$ & $(0.17 ; 0.69)$ \\
$\mathrm{C}_{10}$ & $(0.41 ; 0.13)$ & $(0.41 ; 0.18)$ & $(0.37 ; 0.22)$ & $(0.37 ; 0.18)$ & $(0.50 ; 0.22)$ & $(0.34 ; 0.27)$ \\
\hline
\end{tabular}

Eq. (12) and Eq. (13) were used to normalize the decision matrix. Table 4 shows the normalized decision matrix.

\section{Table 4}

The normalized intuitionistic fuzzy valued decision matrix

\begin{tabular}{cccccc}
\hline & $\mathrm{A}_{1}$ & $\mathrm{~A}_{2}$ & $\mathrm{~A}_{3}$ & $\mathrm{~A}_{4}$ & $\mathrm{~A}_{5}$ \\
\hline $\mathrm{C}_{1}$ & $(0.54 ; 0.35)$ & $(0.47 ; 0.90)$ & $(0.71 ; 0.41)$ & $(0.73 ; 0.42)$ & $(0.59 ; 0.97)$ \\
$\mathrm{C}_{2}$ & $(0.75 ; 0.16)$ & $(0.73 ; 0.82)$ & $(0.91 ; 0.64)$ & $(0.84 ; 0.64)$ & $(0.90 ; 0.73)$ \\
$\mathrm{C}_{3}$ & $(0.93 ; 0.14)$ & $(1.00 ; 0.47)$ & $(1.00 ; 0.52)$ & $(1.00 ; 0.53)$ & $(0.95 ; 0.71)$ \\
$\mathrm{C}_{4}$ & $(0.39 ; 0.93)$ & $(0.40 ; 0.87)$ & $(0.45 ; 1.00)$ & $(0.43 ; 1.00)$ & $(0.45 ; 0.98)$ \\
$\mathrm{C}_{5}$ & $(0.69 ; 0.97)$ & $(0.57 ; 1.00)$ & $(0.58 ; 0.83)$ & $(0.67 ; 0.74)$ & $(0.86 ; 1.00)$ \\
$\mathrm{C}_{6}$ & $(0.66 ; 1.00)$ & $(0.73 ; 0.77)$ & $(0.82 ; 0.88)$ & $(0.80 ; 0.87)$ & $(0.81 ; 0.96)$ \\
$\mathrm{C}_{7}$ & $(1.00 ; 0.31)$ & $(0.78 ; 0.40)$ & $(0.73 ; 0.56)$ & $(0.71 ; 0.57)$ & $(1.00 ; 0.47)$ \\
$\mathrm{C}_{8}$ & $(1.00 ; 0.21)$ & $(1.00 ; 0.26)$ & $(1.00 ; 0.37)$ & $(1.00 ; 0.30)$ & $(0.78 ; 1.00)$ \\
$\mathrm{C}_{9}$ & $(0.41 ; 0.67)$ & $(0.73 ; 0.40)$ & $(0.61 ; 0.57)$ & $(0.56 ; 0.46)$ & $(0.87 ; 0.65)$ \\
$\mathrm{C}_{10}$ & $(0.51 ; 1.00)$ & $(0.75 ; 1.00)$ & $(0.59 ; 1.00)$ & $(0.56 ; 1.00)$ & $(1.00 ; 0.59)$ \\
\hline
\end{tabular}


By considering the different importance of each criterion, we can obtain the weighted normalized intuitionistic fuzzy valued matrix. This matrix is depicted by Table 5 .

Table 5

Weighted normalized decision matrix

\begin{tabular}{cccccc}
\hline & $\mathrm{A}_{1}$ & $\mathrm{~A}_{2}$ & $\mathrm{~A}_{3}$ & $\mathrm{~A}_{4}$ & $\mathrm{~A}_{5}$ \\
\hline $\mathrm{C}_{1}$ & $(0.04 ; 0.02)$ & $(0.03 ; 0.06)$ & $(0.05 ; 0.02)$ & $(0.05 ; 0.02)$ & $(0.04 ; 0.06)$ \\
$\mathrm{C}_{2}$ & $(0.09 ; 0.01)$ & $(0.09 ; 0.06)$ & $(0.11 ; 0.05)$ & $(0.10 ; 0.05)$ & $(0.11 ; 0.05)$ \\
$\mathrm{C}_{3}$ & $(0.07 ; 0.01)$ & $(0.08 ; 0.02)$ & $(0.08 ; 0.03)$ & $(0.08 ; 0.03)$ & $(0.07 ; 0.04)$ \\
$\mathrm{C}_{4}$ & $(0.06 ; 0.04)$ & $(0.06 ; 0.04)$ & $(0.07 ; 0.05)$ & $(0.07 ; 0.05)$ & $(0.07 ; 0.05)$ \\
$\mathrm{C}_{5}$ & $(0.05 ; 0.10)$ & $(0.04 ; 011)$ & $(0.04 ; 0.09)$ & $(0.05 ; 0.08)$ & $(0.06 ; 0.11)$ \\
$\mathrm{C}_{6}$ & $(0.06 ; 0.16)$ & $(0.07 ; 0.12)$ & $(0.08 ; 0.10)$ & $(0.08 ; 0.13)$ & $(0.08 ; 0.15)$ \\
$\mathrm{C}_{7}$ & $(0.13 ; 0.01)$ & $(0.10 ; 0.02)$ & $(0.09 ; 0.02)$ & $(0.09 ; 0.02)$ & $(0.13 ; 0.02)$ \\
$\mathrm{C}_{8}$ & $(0.04 ; 0.02)$ & $(0.07 ; 0.03)$ & $(0.05 ; 0.07)$ & $(0.07 ; 0.04)$ & $(0.05 ; 0.14)$ \\
$\mathrm{C}_{9}$ & $(0.01 ; 0.12)$ & $(0.02 ; 0.07)$ & $(0.02 ; 0.10)$ & $(0.02 ; 0.08)$ & $(0.03 ; 0.11)$ \\
$\mathrm{C}_{10}$ & $(0.04 ; 0.07)$ & $(0.06 ; 0.07)$ & $(0.04 ; 0.07$ & $(0.04 ; 0.08)$ & $(0.08 ; 0.04)$ \\
\hline
\end{tabular}

Euclidean distance from the positive- ideal and negative- ideal alternatives are obtained using Eq. (17) and Eq. (18) formulas, respectively. The results are registered in Table 6.

Table 6

The distance from the ideal solution and negative-ideal solution

\begin{tabular}{lcc}
\hline & $\mathrm{A}^{+}$ & $\mathrm{A}^{-}$ \\
\hline $\mathrm{A}_{1}$ & 0.667 & 0.660 \\
$\mathrm{~A}_{2}$ & 0.665 & 0.663 \\
$\mathrm{~A}_{3}$ & 0.664 & 0.665 \\
$\mathrm{~A}_{4}$ & 0.662 & 0.667 \\
$\mathrm{~A}_{5}$ & 0.669 & 0.658 \\
\hline
\end{tabular}

Finally, the closeness coefficient of each airport is obtained by applying Eq. (19). The results are:

$$
R C_{1}=0.497 R C_{2}=0.499 R C_{3}=0.500 R C_{4}=0.502 R C_{5}=0.459
$$

Therefore, the final ranking is $A_{4} \succ A_{3} \succ A_{2} \succ A_{1} \succ A_{5}$. The final ranking results show that Mohammed $\mathrm{V}$ International Airport is the best of the five airports in terms of service quality, followed by Carthage International Airport, Cairo International Airport, Houari Boumedienne Airport and Tripoli International Airport.

\section{Conclusion}

We have developed a TOPSIS method based on intuitionistic fuzzy values to solve multiple criteria decision making problems characterized by vague human judgments. Via the suggested method, the ratings of alternatives and the importance weights of criteria are normalized into a comparable scale by using arithmetic operations between intuitionistic fuzzy values. A case study aiming to evaluate and compare the service quality of five major North African was conducted to demonstrate the effectiveness of the proposed TOPSIS method. This study helps managers of airports to know the requirements of their customers and the priority of enhancing service items.

\section{References}

Aloini, D., Dulmin, R. \& Mininno, V. (2014), A peer IF-TOPSIS based decision support system for packaging machine selection, Expert Systems with Applications, 41, 2157- 2165.

Atanassov, K. (1986), Intuitionistic fuzzy sets, Fuzzy sets and system, 20, 87-96.

Atanassov, K. (2000). Two theorems for intuitionistic fuzzy sets. Fuzzy Sets and Systems, 110, 267269. 
Boran, F.E., Gen, S., Kurt, M. \& Akay, D. (2009), A multi-criteria intuitionistic fuzzy group decision making for supplier selection with TOPSIS method, Expert Systems with Applications, 36, 1136311368.

Chen, C. T. (2000). Extensions of the TOPSIS for group decision-making under fuzzy environment. Fuzzy Sets and Systems, 114, 1-9.

Chen, C. T., Lin, C. T., \& Huang, S. F. (2006). A fuzzy approach for supplier evaluation and selection in supplier chain management. International Journal of Production Economics, 102(2), 289-301.

Chen, M. F., \& Tzeng, G. H. (2004). Combining grey relation and TOPSIS concepts for selecting an expatriate host country. Mathematical and Computer Modelling, 40,1473-1490.

Chen, S. J., \& Hwang, C. L. (1992). Fuzzy multiple attribute decision making. Berlin: Springer.

Hwang, C., \& Yoon, K. (1981). Multiple attribute decision making: Methods and application. New York: Springer.

Jahanshahloo, G. R., Hosseinzadeh Lotfi, F., \& Izadikhah, M. (2006). Extension of the TOPSIS method for decision-making problems with fuzzy data. Applied Mathematics and Computation, 181, 15441551.

Joshi, D. \& Kumar, S. (2014), Intuitionistic fuzzy entropy and distance measure based TOPSIS method for multi criteria decision making. Egyptian informatics Journal, 15, 97-104.

Kuo, M. S., Tzeng, G. H., \& Huang, W. C. (2007). Group decision-making based on concepts of ideal and anti-ideal points in a fuzzy environment. Mathematical and Computer Modelling, 45, 324-339.

Kuo, M. S., Tzeng, G. H., \& Huang, W. C. (2007). Group decision-making based on concepts of ideal and anti-ideal points in a fuzzy environment. Mathematical and Computer Modelling, 45, 324-339.

Liang, G. S. (1999). Fuzzy MCDM based on ideal and anti-ideal concepts. European Journal of Operational Research, 112, 682-691.

Tan, C. \& Chen, X. (2010), Intuitionistic fuzzy Choquet integral operator for multi-criteria decision making, Expert Systems with Applications, 37, 149-157.

Wang, T. C., \& Chang, T. H. (2007). Application of TOPSIS in evaluating initial training aircraft under a fuzzy environment. Expert Systems with Applications, 33, 870-880.

Wang, Y. J., \& Lee, H. S. (2007). Generalizing TOPSIS for fuzzy multiple-criteria group decisionmaking. Computers and Mathematics with Applications, 53, 1762-1772.

Wang, Y. M., \& Elhag, T. M. S. (2006). On the normalization of interval and fuzzy weights. Fuzzy Sets and Systems, 157, 2456-2471.

Wei, G., Zhao, X. \& Lin, R. (2013), Some hesitant interval-valued fuzzy aggregation operators and their applications in multiple attribute decision making, Knowledge- Based Systems, 46, 45-53.

Xu, Z.S. (2007), Methods for aggregating interval-valued intuitionistic fuzzy information and their application to decision making. Control and Decision, 2, 22, 215-219.

Yeh, C. H., \& Deng, H. (2004). A practical approach to fuzzy utilities comparison in fuzzy multicriteria analysis. International Journal of Approximate Reasoning, 35, 179-194.

Yeh, C. H., Deng, H., \& Chang, Y. H. (2000). Fuzzy multicriteria analysis for performance evaluation of bus companies. European Journal of Operational Research, 126, 459-473.

Zadeh, L. A. (1965). Fuzzy sets. Information and Control, 8, 338-353.

Zhang, H. \& Liying, Y. (2012), MADM method based on cross-entropy and extended TOPSIS with interval-valued intuitionistic fuzzy sets, Knowledge-Based Systems, 30, 115-120.

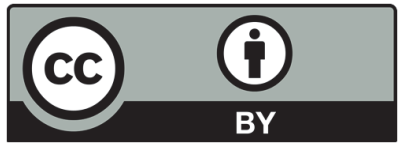

(C) 2017 by the authors; licensee Growing Science, Canada. This is an open access article distributed under the terms and conditions of the Creative Commons Attribution (CC-BY) license (http://creativecommons.org/licenses/by/4.0/). 